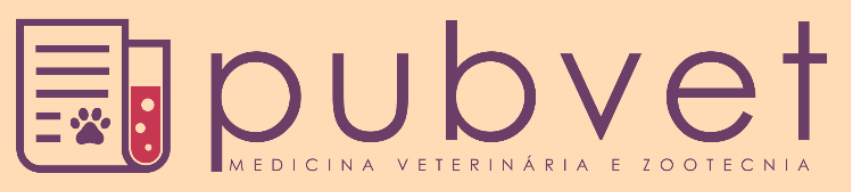

https://doi.org/10.31533/pubvet.v13n3a291.1-10

\title{
Produção de fitase por Aspergillus niger var. phoenicis URM 4924 utilizando planejamentos fatoriais
}

\author{
Júlio Cézar dos Santos Nascimento ${ }^{1 *} \bullet$, Vanessa Maranhão Soares ${ }^{2} \bullet$, Lourival Barros Sousa de Brito \\ Pereira $^{30}$, Lucilo Bioni Filho $^{4} \bullet$, Priscila Virgínio de Albuquerque ${ }^{5}$, Gilcifran Prestes de Andrade ${ }^{50}$, Hilton

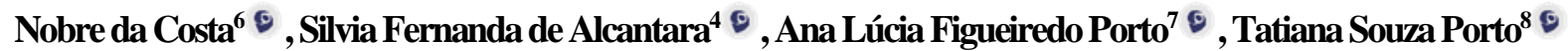 \\ ${ }^{1}$ Professor adjunto da Universidade Federal Rural de Pernambuco, Departamento de Zootecnia. Recife -PE, Brasil. \\ ${ }^{2}$ Discente da curso de Medicina Veterinária da Universidade Maurício de Nassau (UNINASSAU). Recife-PE, Brasil. \\ ${ }^{3}$ Médico veterinário autônomo. Recife-PE Brasil. \\ ${ }^{4}$ Mestrando no Programa de Pós-Graduação em Ciência animal tropical da Universidade Rural de Pernambuco. Recife-PE, Brasil. \\ ${ }^{5}$ Doutorando no Programa de Pós-graduação em Ciência animal da Universidade Rural de Pernambuco. Recife-PE, Brasil. \\ ${ }^{6}$ Doutorando no Programa de Pós-Graduação em Entomologia agrícola da Universidade Rural de Pernambuco. Recife-PE, Brasil. \\ ${ }^{7}$ Professora titular da Universidade Rural de Pernambuco, Departamento de Morfologia e Fisiologia Animal. Recife-PE, Brasil. \\ ${ }^{8}$ Professora associada na Unidade acadêmica de Garanhuns da Universidade Federal Rural de Pernambuco. Garanhuns-PE, Brasil. \\ *Autor para correspondência, E-mail: juliocezarsantosnascimento@gmail.com
}

Resumo. Os fitatos representam uma classe complexa de compostos de ocorrência natural formados durante o processo de maturação de sementes e grãos de cereais, sendo a principal forma de armazenamento de fósforo em vegetais. A molécula de fitato é um grande fator antinutricional para monogástricos, possuindo em sua estrutura grupos ortofosfatos altamente ionizáveis, os quais afetam a disponibilidade de minerais no trato gastrointestinal. Fitases formam um grupo de enzimas com a capacidade de liberar o fósforo ligado à molécula do fitato, com a finalidade de aumentar o aproveitamento do fósforo para absorção. O objetivo deste trabalho foi avaliar parâmetros do meio de cultivo, tais como a concentração da fonte de nitrogênio e da fonte de carbono na produção de fitase por Aspergillus niger var. phoenicis URM 4924, utilizando planejamento fatorial. Para avaliar a influência de parâmetros do meio de cultivo na produção de fitase, realizou-se planejamento fatorial e metodologia de superfície de resposta. As melhores condições para a produção de fitase $(8,80 \mathrm{U} / \mathrm{mL})$ em fermentação submersa por A. niger var. phoenicis URM 4924 foram, 1,25\% da fonte de carbono (farelo de arroz) e 3,0\% da fonte de nitrogênio (milhocina). A. niger var. phoenicis URM 4924 apresentou potencial biotecnológico para produção de fitase que poderão ser adicionadas a alimentação de animais não-ruminantes, desta maneira, contribuindo para o aumento do aproveitamento de nutrientes e nos índices de produção.

Palavras chave: fitase, metodologia de superfície de resposta, planejamentos fatoriais

\section{Phytase production by Aspergillus niger var. phoenicis URM 4924 using factorial planning}

Abstract. Phytates represent a complex class of natural occurring compounds formed during the maturation process of seeds and grains, the main storage form of phosphorus in vegetables. The phytate molecule is a major anti-nutritional factor for monogastrics animals, possessing in their structure highly ionizable groups orthophosphate, which affect the availability of minerals in the gastrointestinal tract. Phytases form a group of enzymes with the ability to release phosphorus bound to phytate molecule, with the aim of increasing the utilization of phosphorus for absorption. The aim of this study was to evaluate parameters of the medium, such as the concentration of nitrogen and carbon source in the 
production of phytase by Aspergillus niger var. phoenicis URM 4924, using a factorial design. To evaluate the influence of parameters of the culture medium in the production of phytase was carried out factorial design and response surface methodology. The best conditions for production of phytase $(8.80 \mathrm{U} / \mathrm{mL})$ in submerged fermentation by A. niger var. phoenicis URM 4924 were $1.25 \%$ of the carbon source (rice bran) and $3.0 \%$ nitrogen source (corn steep liquor). A. niger var. phoenicis URM 4924 has potential for biotechnological production of phytase can be added to feed non-ruminant animals, thus contributing to the increased use of nutrients and production rates.

Keywords: phytase, response surface methodology, factorial designs

\section{Producción de fitasa por Aspergillus niger var. phoenicis URM 4924 utilizando planificaciones factoriales.}

Resumen. Los fitatos representan un complejo de clase de compuestos naturales formadas durante el proceso de maduración de las semillas y granos de cereales, siendo la principal forma de almacenamiento del fósforo en las plantas. La molécula de fitato es un gran factor anti nutricional para monogástricos, teniendo en su estructura grupos ortofosfatos altamente ionizables, que afectan la disponibilidad de minerales en el tracto gastrointestinal. Fitasas constituyen un grupo de enzimas con capacidad para liberar el fósforo acoplado a la molécula de fitato, con el objetivo de aumentar la utilización del fósforo de absorción. El objetivo de este trabajo fue evaluar los parámetros del medio de cultivo, tales como la concentración de la fuente de nitrógeno y fuente de carbono para la producción de fitasa por Aspergillus niger var. phoenicis URM 4924, mediante diseño factorial. Para evaluar la influencia de parámetros del medio de cultivo en la producción de fitasa, se realizó una planificación factorial y metodología de superficie de respuesta. Las mejores condiciones para la producción de fitasa $(8,80 \mathrm{U} / \mathrm{mL})$ en fermentación sumergida por A. niger var. phoenicis URM 4924 fueron, 1,25\% de la fuente de carbono (salvado de arroz) y el 3,0\% de la fuente de nitrógeno (licor de maíz fermentado). A. niger var. phoenicis URM 4924 presentó potencial biotecnológico para la producción de fitasa que podrían añadirse a la alimentación de animales no rumiantes, contribuyendo así al aumento del aprovechamiento de nutrientes y de los índices de producción.

Palabras clave: fitasa, metodología de superficie de respuesta, planificaciones factoriales

\section{Introdução}

Ácido fítico ou fitato é a principal forma de armazenamento de fosfato e de inositol em plantas e existe naturalmente complexado com uma série de minerais essenciais e proteínas (Luo et al., 2007; Zhang et al., 2010). Entretanto, o fósforo presente no ácido fítico não pode ser aproveitado por animais não ruminantes, pois estes não sintetizam a enzima capaz de efetuar a hidrólise do fitato (Lei \& Porres, 2003). Além disso, o fitato nos alimentos é caracterizado como um fator anti nutricional, pois possui a capacidade de ligar-se a minerais essenciais e proteínas, diminuindo assim, a disponibilidade dos ingredientes de origem vegetal (Kim et al., 1999). Com o intuito de diminuir os efeitos das altas concentrações de fitato, a ração os suínos, aves e peixes têm sido suplementados com fitase, enzima que atua na degradação do fitato (Choi et al., 2001). As fitases podem ser encontradas em plantas, animais e microrganismos (Fan et al., 2013). Os fungos filamentosos do gênero Aspergillus são os microrganismos que possuem maior destaque na produção industrial de fitases (Vats \& Banerjee, 2004).

A otimização da composição do meio de cultivo para obter-se máximo rendimento em produto é uma difícil etapa na produção de uma biomolécula. Um procedimento que pode ser utilizado na otimização de meios em bioprocessos é a utilização de planejamentos fatoriais. Após seleção dos principais componentes do meio que afetam o rendimento em produto e a produtividade, procede-se a combinação dos mesmos de acordo com uma metodologia estatística. Desta forma, os efeitos de vários componentes podem ser determinados simultaneamente, com um número relativamente pequeno de experimentos (Pereira Junior, 2008). 
O objetivo deste trabalho foi avaliar parâmetros do meio de cultivo, tais como concentração da fonte de nitrogênio e de carbono na produção de fitase por Aspergillus niger var. phoenicis URM 4924 em fermentação submersa, utilizando planejamento fatorial e metodologia de superfície resposta.

\section{Material e métodos}

O fungo utilizado para a produção da fitase foi o Aspergillus niger var. phoenicis URM 4924, cedido pela coleção de culturas URM do Departamento de Micologia - UFPE. O meio de cultura utilizado para a manutenção do A. niger var. phoenicis URM 4924 foi o Ágar Extrato de Malte [extrato de malte (2\%), peptona $(0,1 \%)$, glicose $(2 \%)$ e ágar $(1,5 \%)]$. O meio de cultura utilizado para esporulação foi ágar Czapek [3\% de sacarose (p/v), nitrato de sódio $0,3 \%(\mathrm{p} / \mathrm{v})$, sulfato de magnésio 0,05\% (p/v), cloreto de potássio $0,05 \%(\mathrm{p} / \mathrm{v})$, sulfato ferroso $0,001 \%(\mathrm{p} / \mathrm{v})$, ágar $1,6 \%(\mathrm{p} / \mathrm{v})]$. A esterilização dos meios de cultura foi realizada em autoclave a $121^{\circ} \mathrm{C}$, um atm de pressão, durante 20 minutos.

Todos os reagentes utilizados foram de grau analítico obtidos da Sigma (St. Louis, MO, USA). Todas as soluções utilizaram água ultra-pura, devido à grande quantidade de fósforo inorgânico presente nos demais tipos de água.

A. niger var. phoenicis URM 4924 foi repicado em tubos de ensaio contendo meio de cultura ágar Czapek incubados a $30^{\circ} \mathrm{C}$ em estufa por 7 (sete) dias até ocorrer esporulação. A dispersão dos esporos foi obtida através da adição de solução salina $0,9 \%(\mathrm{p} / \mathrm{v})$ e Tween $80(0,1 \% \mathrm{p} / \mathrm{v})$ previamente esterilizada, após a dispersão dos esporos por agitação com auxílio do vortex foi realizada contagem em câmara de Neubauer para posterior inoculação no meio de cultivo. A concentração do inóculo foi de $10^{6}$ esporos/mL.

Para a realização dos ensaios de produção de fitase $(\mathrm{U} / \mathrm{mL})$ foram realizadas fermentações submersas. Foi realizada a seleção da fonte de nitrogênio (milhocina, ureia ou extrato de levedura) para o crescimento microbiano e produção de fitases.

Foram utilizadas as fontes anteriormente citadas associada com a fonte de carbono (farelo de arroz a $0,5 \%$ ), acrescido de solução salina (composição $\mathrm{gL}^{-1}: \mathrm{KCl} 0,5 ; \mathrm{MgSO}_{4} \cdot 7 \mathrm{H}_{2} \mathrm{O} 1,5 ; \mathrm{CaCl}_{2} \cdot 2 \mathrm{H}_{2} \mathrm{O} 2,0$ ) por $60,72,84,96,120$ horas em agitador orbital $(90 \mathrm{rpm}), \mathrm{pH} 5,0$ a $30^{\circ} \mathrm{C}$.

A atividade fitásica foi determinada pela mensuração da quantidade de fósforo inorgânico liberado, baseado no método modificado proposto por Heinonen \& Lahti (1981). Foram incubados $350 \mu \mathrm{L}$ de fitato de sódio ( $875 \eta \mathrm{M}$, em tampão acetato $\mathrm{pH} 4,5)$ e $50 \mu \mathrm{L}$ do extrato bruto enzimático na temperatura de $37^{\circ} \mathrm{C}$ por 30 minutos. A reação foi parada pela adição de $1,5 \mathrm{~mL}$ da solução AAM (molibdato de amônio $10 \mathrm{mM}$, ácido sulfúrico 5,0 $\mathrm{N}$ e acetona na proporção 1:1:2). Em seguida, adiciona-se $100 \mu \mathrm{L}$ de ácido cítrico, $1 \mathrm{M}$ foi adicionada. Uma unidade de atividade enzimática foi definida como a quantidade de enzima capaz de liberar $1,0 \mu \mathrm{mol}$ de fosfato inorgânico por minuto sob condições de reações definidas. Todas as análises foram realizadas em triplicata.

O fósforo inorgânico do extrato enzimático foi determinado utilizando água ultrapura (350 $\mu \mathrm{L})$ mais o extrato enzimático $(50 \mu \mathrm{L})$ acrescido da solução AAM e ácido cítrico $1 \mathrm{M}$ como descrito pelo método anteriormente citado. A quantidade de fósforo total para o cálculo da atividade fitásica foi o valor obtido no ensaio da determinação quantitativa subtraído da quantidade de fósforo inorgânico contido no extrato bruto. Todas as análises foram realizadas em triplicata.

Para avaliar a influência de parâmetros do meio de cultivo, realizaram-se planejamentos fatoriais, foram analisados os efeitos das fontes de carbono (farelo de arroz) e da fonte de nitrogênio (milhocina) na produção de fitase. Os nutrientes do meio de cultura foram selecionados em experimento prévios e foi elaborada uma matriz do planejamento fatorial completo $\left(2^{2}\right)$, para estudar a influência das concentrações da fonte de nitrogênio $(\% F N=1,0 ; 1,5$ e 2,0\%) e da fonte de carbono ( $\% F C=0,25,0,5$ e $0,75 \%$ ) sobre a produção de fitases $(\mathrm{U} / \mathrm{mL})$ em 60,72 e 84 horas.

Sequencialmente foi realizado um experimento denominado caminho da máxima inclinação, onde a resposta varia de forma mais pronunciada (Barros Neto et al., 2003). Com o objetivo de determinar as melhores condições para a produção de fitase, realizou-se a metodologia de superfície de resposta (MSR). As análises das atividades foram realizadas em triplicata. Todas as análises estatísticas e gráficas foram realizadas utilizando o auxílio do software Statistica 8.0 (SAS, 2004). 


\section{Resultados e discussão}

Inicialmente foram avaliadas diferentes fontes de nitrogênio e observou-se que a melhor produção de fitase $(6,60 \mathrm{U} / \mathrm{mL})$ foi encontrada em meios de cultivo contendo milhocina a $1,5 \%$ e com farelo de arroz a $0,5 \%$ em 72 horas de fermentação submersa.

Várias pesquisas têm sido realizadas com o intuito de estudar a influência de fontes de nitrogênio em fermentação para a produção de enzimas por fungos filamentosos. Bertolin et al. (2003) e Anto et al. (2006) utilizaram ureia e sulfato de amônio como fontes de nitrogênio, no entanto estes autores verificaram o aumento da produção da enzima estudada com o uso de ureia.

Todavia, no presente trabalho encontraram-se resultados distintos dos autores supracitados, a produção de fitase diminuiu com a adição de ureia e aumentou com a inclusão de milhocina. Fato esse, que pode ser explicado pela maior assimilação do nitrogênio da milhocina pelo A. niger var. phoenicis URM 4924, quando comparado com a assimilação da ureia, pois a milhocina tem a composição química mais rica quando comparado a ureia.

A milhocina é um subproduto da produção de amido de milho. Industrialmente, o milho seco é macerado em uma solução de ácido sulfúrico a elevadas temperaturas, sua fração solúvel sofre uma suave fermentação láctica natural que ocorre devido à presença de bactérias na solução, é então, submetida a uma operação de evaporação, na qual a milhocina é concentrada, sendo usada principalmente como suplemento alimentício para ruminantes, fonte de nutrientes para aves, na confecção de iscas atrativas para as moscas das frutas e fonte de nutrientes para o processo de fermentação industrial (Filipović et al., 2001). A composição da milhocina é muito variável, dependendo da origem da matéria-prima e de seu processamento. Dentre os compostos variados encontram-se íons metálicos, vitaminas e outros compostos em pequenas quantidades.

Lan et al. (2002) utilizaram o farelo de arroz para fermentação com Mitsuokella jalaludini e verificaram que o aumento na produção da fitase $(10,69 \mathrm{U} / \mathrm{g})$, visto que este farelo possui alto teor de ácido fítico. $\mathrm{O}$ farelo de arroz é, entre os alimentos de origem vegetal, o que possui uma das maiores porcentagens de fósforo total (1,5\%), enquanto o milho possui $0,28 \%$ e o farelo de soja, $0,65 \%$ (NRC, 1994). Por outro lado, é o alimento que possui uma das menores taxas de disponibilidade de fósforo, devido ao seu alto teor de fitato. Segundo Rostagno et al. (2017), o farelo de arroz tem de 5,1\% a 8,6\% de fitato na sua composição, embora os demais cereais possuam entre $1 \%$ e $2 \%$ de fitato.

Papagianni et al. (1999) encontraram diferentes resultados para a produção de fitase por A. niger. Esses autores constataram que a otimização da produção de fitase por A. niger foi realizada usando farelo de trigo, acrescido de meio semi-sintético, composto por amido de milho, glicose e peptona. ElGindy et al. (2009) avaliaram a produção de fitase extracelular por Malbranchea sulfurea e A. niveus, testando meios de cultura compostos por extrato de levedura, extrato de malte, milhocina, melaço de cana-de-açúcar e soro de leite. Os mesmos destacam o efeito da inclusão da milhocina, pois observaram o aumento da produção de fitase por $M$. sulfurea $2,89 \mathrm{U} / \mathrm{g}$ em fermentação no estado sólido.

A produção de enzimas extracelulares tem sido comum por muitas espécies de fungos filamentosos como resposta a determinados estímulos ambientais, pela expressão de genes e posterior secreção das enzimas fornecidas. A síntese dessas enzimas está sujeita aos diversos mecanismos de regulação passíveis de indução e repressão, sendo a secreção direcionada por peptídeos sinal, que fazem parte da proteína a ser exportada, e que ao serem reconhecidos pela célula garantem a passagem pelo canal exportador (Tirado-González et al., 2016). Após a análise dos resultados da seleção da fonte de nitrogênio, experimentos foram realizados com o intuito de melhorar as condições de produção da fitase produzida por A. niger var. phoenicis URM 4924, no qual selecionou-se fonte de nitrogênio (\%FNmilhocina), associada a fonte de carbono e fósforo ( $\% F C$ - farelo de arroz). Foi realizado o planejamento fatorial $2^{2}$ para melhorar as condições da produção de fitase. Observou-se que as melhores condições de produção foram obtidas com o meio contendo as seguintes características: \% FC 0,75 e \%FN 2,0 em 84 horas de produção. Na Tabela 1 encontram-se os resultados do planejamento fatorial completo $2^{2}$. 
Tabela 1. Produção de fitase por Aspergillus niger var. phoenicis URM 4924, utilizando planejamento fatorial $\left(2^{2}\right)$ para avaliar a influência das variáveis da concentração da fonte de carbono e concentração da fonte de nitrogênio na produção de fitases $(\mathrm{U} / \mathrm{mL})$.

\begin{tabular}{llllll}
\hline Experimentos & $\% F C$ & $\% F N$ & $60 \mathrm{~h}$ & $72 \mathrm{~h}$ & $84 \mathrm{~h}$ \\
\hline 1 & 0,25 & 1,0 & 5,24 & 4,61 & 2,75 \\
2 & 0,75 & 1,0 & 6,75 & 7,60 & 7,88 \\
3 & 0,25 & 2,0 & 8,10 & 7,41 & 5,90 \\
4 & 0,75 & 2,0 & 9,94 & 10,80 & 11,67 \\
5 & 0,5 & 1,5 & 6,27 & 6,84 & 6,31 \\
6 & 0,5 & 1,5 & 6,42 & 6,71 & 6,22 \\
7 & 0,5 & 1,5 & 6,42 & 6,69 & 5,77 \\
8 & 0,5 & 1,5 & 6,55 & 6,73 & 5,91 \\
\hline
\end{tabular}

$\% F C$ - concentração da fonte de carbono (farelo de arroz), \%FN - concentração da fonte de nitrogênio (milhocina)

Adinarayana \& Ellaiah (2003) estudaram os componentes do meio de cultivo para produção de protease utilizando planejamento fatorial completo $2^{3}$. Segundo os autores, o método foi eficiente, pois somente 12 experimentos foram necessários para determinar as condições ótimas, o modelo descrito foi satisfatório. Lan et al. (2002) estudaram a influência das fontes de carbono e nitrogênio na produção de fitase por Mitsuokella jalaludini, uma bactéria isolada do suco ruminal do gado bovino, a qual se mostrou capaz de hidrolisar o fitato (in vitro). Eles testaram diversos ingredientes de origem vegetal (farelo de arroz, torta de dendê e melaço), acrescido de fontes de nitrogênio (peptona, extrato de levedura e leite de soja) e fontes de carbono (glicose, celobiose e amido solúvel). A melhor condição encontrada foi à combinação de farelo de arroz e leite de soja obtendo 11,63 U/L em 12 horas de fermentação submersa a $39^{\circ} \mathrm{C}$.

Shah et al. (2009) obtiveram valor de $6,18 \mathrm{U} / \mathrm{mL}$ na produção de fitase extracelular por A. niger NCIM 563 em fermentação submersa, utilizando farelo de arroz (1\%) e 144 horas de cultivo. Vale salientar que o tempo é um fator muito importante para a produção enzimática, pois quanto menor o tempo, maior será a eficiência do processo. Então, os resultados do presente trabalho são mais satisfatórios, pois, verificou-se uma maior produção de fitase $(11,67 \mathrm{U} / \mathrm{mL})$ em menor tempo de cultivo (84 horas).

$\mathrm{Na}$ análise dos efeitos das variáveis (Tabela 2), verificou-se que as variáveis estudadas apresentaram efeitos significativos e positivos em todos os tempos de produção. A interação entre a concentração da fonte de carbono (1) e a concentração da fonte de nitrogênio (2), não apresentou efeitos significativos. Isto mostra que com o aumento da concentração da fonte de carbono e da concentração da fonte de nitrogênio há uma tendência para o aumento da produção de fitase $(\mathrm{U} / \mathrm{mL})$.

Tabela 2. Efeito calculado das respostas do planejamento fatorial $2^{2}$ para produção de fitase Aspergillus niger var. phoenicis URM 4924.

\begin{tabular}{llll}
\hline Efeitos & $60 \mathrm{~h}$ & $72 \mathrm{~h}$ & $84 \mathrm{~h}$ \\
\hline$\% F C(1)$ & $14,74^{\mathrm{a}}$ & $48,48^{\mathrm{a}}$ & $21,48^{\mathrm{a}}$ \\
$\% F N(2)$ & $26,75^{\mathrm{a}}$ & $45,47^{\mathrm{a}}$ & $13,67^{\mathrm{a}}$ \\
$1 \times 2$ & 1,45 & 3,00 & 1,24 \\
\hline
\end{tabular}

${ }^{a}$ Valores estatisticamente significativos (95\% de confiança). \%FC - concentração da fonte de carbono (1) e \% $F N$ - concentração da fonte de nitrogênio (2).

Marlida et al. (2010) trabalharam com o isolamento, caracterização e produção de fitase por fungos filamentosos endofíticos isolados da soja (Glycine max) e selecionaram Rhizoctonia sp. e Fusarium verticillioides como os mais eficientes na produção de fitase, pois apresentaram produção de fitase de 2,72 e $6,11 \mathrm{U} / \mathrm{mL}$ respectivamente, em $28^{\circ} \mathrm{C}$ por 48 horas. Thyagaraj Namasivayam (2010) estudaram a influência da fonte de carbono para a produção de fitase por Aspergillus niger em fermentação submersa. Os mesmos testaram a inclusão de frutose, maltose, lactose e sacarose, como fontes de carbono, na concentração de 5\%. Os melhores resultados de produção foram encontrados usando o meio basal padrão (g/l: amido, 28; glucose, 5; peptona,18; cloreto de potássio, 0,5; sulfato de magnésio, 1,5; fosfato de potássio dibásico, 1; cloreto de cálcio, 2) acrescido de frutose e sacarose, ambos apresentando valores de 33,33 $\mathrm{U} / \mathrm{mL}$. 
Na Tabela 3 estão apresentados os resultados do caminho da máxima inclinação correlacionando as variáveis $\% F C$ e $\% F N$. Este ensaio é decorrente das melhores condições obtidas no planejamento fatorial $2^{2}$, que corresponderam aos maiores níveis estudados. O caminho da máxima inclinação parte do melhor ponto de produção e se desloca na direção indicada pelo planejamento fatorial para verificar qual o valor máximo destas variáveis em estudo. Pode-se observar que a melhor condição determinada pelo caminho de máxima inclinação foi obtida com concentração de fonte de carbono de 1,25\% e 3,0\% de fonte de nitrogênio em todos os tempos estudados, sendo 60 horas o melhor tempo de produção. Nesta condição, a atividade fitásica obtida foi de $8,58 \mathrm{U} / \mathrm{mL}$.

Tabela 3. Produção de fitase (U/mL) produzida por Aspergillus niger var.phoenicis URM 4924 obtida no caminho da máxima inclinação

\begin{tabular}{cccccc}
\hline Experimentos & $\% F C$ & $\% F N$ & $60 \mathrm{~h}$ & $72 \mathrm{~h}$ & $84 \mathrm{~h}$ \\
\hline 1 & 0,75 & 2,0 & 5,71 & 5,79 & 5,37 \\
2 & 1,0 & 2,5 & 6,66 & 7,35 & 5,17 \\
3 & 1,25 & 3,0 & 8,58 & 8,51 & 6,24 \\
4 & 1,5 & 3,5 & 4,05 & 2,81 & 1,32 \\
5 & 1,75 & 4,0 & 3,65 & 2,00 & 1,12 \\
6 & 2,0 & 4,5 & 0,83 & 0,73 & 0,31 \\
\hline
\end{tabular}

$\% F C$ - concentração da fonte de carbono (farelo de arroz), \%FN - concentração da fonte de nitrogênio (milhocina).

Soni \& Khire (2007) encontraram 10,47 U/mL como o maior valor de atividade para a produção de fitase por A. niger NCIM 563 em fermentação submersa, quando utilizaram dextrina como fonte de carbono e nitrato de sódio como fonte de nitrogênio. Esses valores de atividade fitásica corroboram com os dados presentes neste estudo.

A partir dos dados obtidos na curva de máxima inclinação foi realizada a metodologia de superfície resposta com o intuito de obter as condições máximas de produção de fitase por A. niger var. phoenicis URM 4924. A metodologia de superfície de resposta (MSR) é aplicada em experimentos industriais para encontrar condições ótimas para fatores de delineamento. É atualmente, o mais popular conjunto de técnicas para otimização, sendo composta de duas etapas: modelagem e deslocamento. $\mathrm{O}$ desenvolvimento de novos produtos biotecnológicos, além de considerações técnicas, legais e mercadológicas, requer também processos de otimização que possam buscar melhores condições de processamento e formulação, com alta qualidade e baixo custo (Castro et al., 2003).

Em muitos casos, a interação de parâmetros que influenciam processos fermentativos pode ser avaliada com um número reduzido de ensaios através de um planejamento experimental. Em relação às enzimas, a metodologia de superfície de resposta é frequentemente utilizada para a otimização e verificação da influência dos componentes do meio de cultivo (Fleuri \& Sato, 2008).

$\mathrm{Na}$ Tabela 4 estão descritos os valores da atividade fitásica $(\mathrm{U} / \mathrm{mL})$ obtidos no experimento da metodologia de superfície de resposta. Observa-se que o valor ótimo da produção da fitase por A. niger var. phoenicis URM 4924 estavam localizados nos ensaios correspondentes ao ponto central, os quais são compostos: concentração da fonte de carbono $(1,25 \%)$ e concentração da fonte de nitrogênio $(3,0 \%)$.

Singh \& Satyanarayana (2009) estudaram variáveis para produção de fitase pelo fungo termofílico Sporotrichum thermophile em fermentação submersa. Os fatores mais significativos identificados pelo planejamento Plackett-Burmann que afetaram a produção de fitase foram amido solúvel, peptona, Tween $80(0,1 \%$ p/v) e fitato de sódio. Um planejamento estatístico do tipo 24 foi aplicado para as variáveis significativas e para delinear suas interações. As concentrações de amido, Tween- $80(0,1 \%$ $\mathrm{p} / \mathrm{v}$ ), peptona e fitato de sódio correspondentes à máxima atividade da enzima foram $0,4 \%, 1,0 \%, 0,3 \%$ e $0,3 \%$, respectivamente. Quando o fitato de sódio foi substituído por farelo de trigo (3,0\%), a atividade da fitase obtida foi semelhante. Portanto, o fitato poderia ser substituído pelo farelo, diminuindo os custos da fermentação.

Nampoothiri et al. (2004) avaliaram a produção de uma fitase termoestável pelo Thermoascus aurantiacus em fermentação submersa. Os autores encontraram valores de 468,22 U/mL de produção de fitase por T. aurantiacus, usando 3,75\% de farelo de arroz em 72 horas de fermentação submersa. Quando a concentração do farelo de arroz foi aumentada para 5,0\% a produção diminuiu para 104,26 
$\mathrm{U} / \mathrm{mL}$, demonstrando o efeito negativo para esta fonte de carbono. Todavia no presente estudo, a produção de fitase aumentou até a inclusão de $1,25 \%$ do farelo de arroz no meio de cultivo $(8,80 \mathrm{U} / \mathrm{mL})$, diminuindo quando se utilizou $1,5 \%(2,84 \mathrm{U} / \mathrm{mL})$.

Tabela 4. Produção de fitase por Aspergillus niger var. phoenicis URM 4924 obtida nos ensaios de metodologia de superfície de resposta em diferentes níveis da concentração da fonte de carbono e concentração da fonte de nitrogênio

\begin{tabular}{lccccc}
\hline Experimentos & $\% F C$ & $\% F C$ & $\% F N$ & $\% F N$ & $\mathrm{AF}(\mathrm{U} / \mathrm{ml})$ \\
\hline 1 & -1 & 1,0 & -1 & 2,5 & 5,90 \\
2 & -1 & 1,0 & +1 & 3,5 & 2,85 \\
3 & +1 & 1,5 & -1 & 2,5 & 5,87 \\
4 & +1 & 1,5 & +1 & 3,5 & 2,84 \\
5 & $-\alpha$ & 0,9 & 0 & 3,0 & 7,82 \\
6 & $+\alpha$ & 1,6 & 0 & 3,0 & 8,50 \\
7 & 0 & 1,25 & $-\alpha$ & 2,3 & 4,35 \\
8 & 0 & 1,25 & $+\alpha$ & 3,7 & 1,39 \\
$9(\mathrm{C})$ & 0 & 1,25 & 0 & 3,0 & 8,78 \\
$10(\mathrm{C})$ & 0 & 1,25 & 0 & 3,0 & 8,72 \\
$11(\mathrm{C})$ & 0 & 1,25 & 0 & 3,0 & 8,80 \\
$12(\mathrm{C})$ & 0 & 1,25 & 3,0 & 8,80 \\
\hline
\end{tabular}

$\% F C$ - concentração da fonte de carbono (farelo de arroz); \%FN - concentração da fonte de nitrogênio (milhocina); AF - atividade fitásica.

A figura 1 apresenta o gráfico de Pareto dos efeitos das variáveis avaliadas na superfície de resposta para produção de fitase $(\mathrm{U} / \mathrm{mL})$.

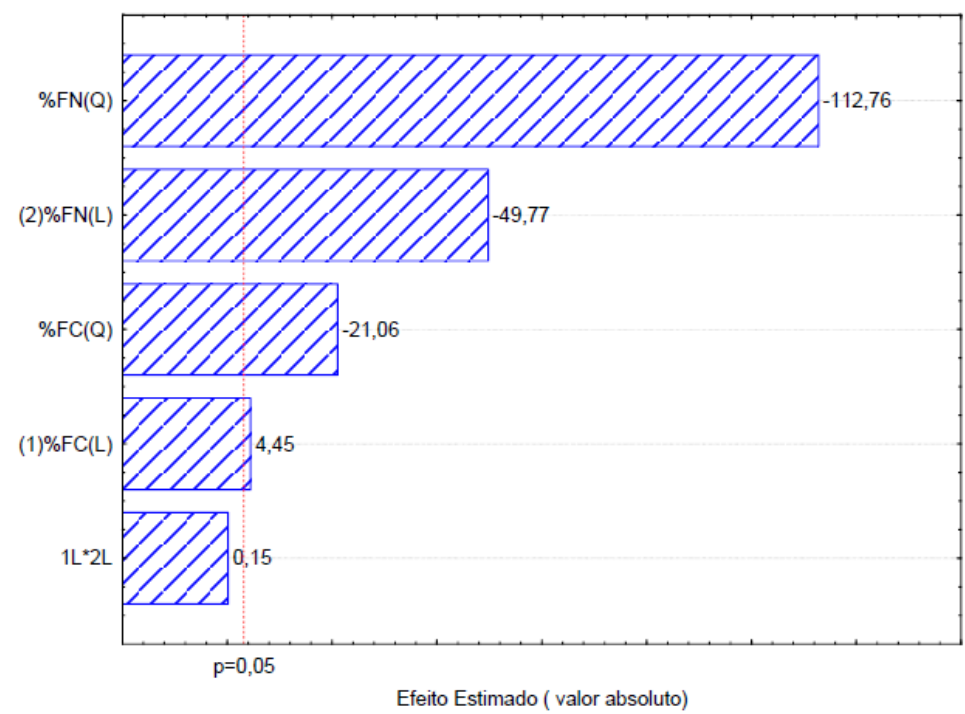

Figura 1. Gráfico de Pareto dos efeitos das variáveis para produção de fitase. $\% F C$ - concentração da fonte de carbono em $\% F N$ - concentração da fonte de nitrogênio.

Observa-se que os efeitos quadráticos e lineares foram estatisticamente significativos para a variável concentração da fonte de nitrogênio, sendo que o modelo quadrático apresentou um efeito negativo, enquanto o linear foi positivo. O efeito da concentração da fonte de carbono, também foi estatisticamente significativo, tanto para o modelo quadrático, como para o linear (Figura 1).

Na figura 2 observa-se o gráfico de projeção da superfície de resposta em função dos fatores experimentais: concentração da fonte de nitrogênio $(\% F N)$ e concentração da fonte de carbono $(\% F C)$. Pode-se verificar que as melhores condições para a produção de fitase em fermentação submersa por $A$. niger var. phoenicis URM 4924 foram $\% F C 1,25$ e $\% F N ~ 3,0$, observou-se que a melhor produção de fitase correspondeu a região central da matriz do planejamento. 


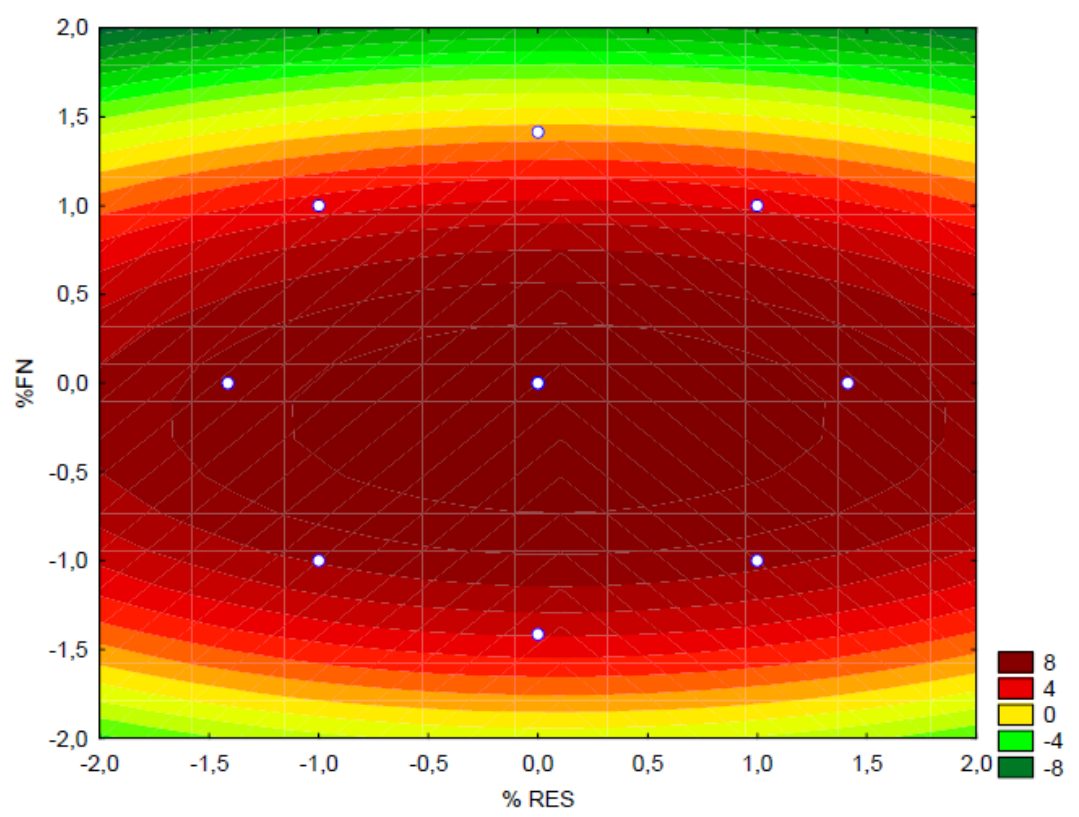

Figura 2. Gráfico de projeção de superfície de resposta para a produção de fitase realizada em função dos fatores experimentais (concentração da fonte de carbono e concentração da fonte de nitrogênio).

Dahiya et al. (2009) investigaram a otimização dos parâmetros de crescimento e de produção de fitase por fungos filamentosos, usando a metodologia de superfície de resposta. Os mesmos avaliaram as variáveis $\mathrm{pH}$, temperatura, concentração da fonte de carbono. Com relação a esta última, sendo que a melhor faixa para produção foi entre 0,27 e $0,3 \%$ da fonte de carbono. Porém, o presente trabalho encontrou um resultado distinto, apresentando maior produção de fitase com uma maior porcentagem de fonte de carbono, que foi de $1,25 \%$, confirmando os dados encontrados na curva da máxima inclinação.

\section{Conclusão}

As melhores condições para a produção de fitase em fermentação submersa por Aspergillus niger var. phoenicis URM 4924 foram, 1,25\% da fonte de carbono (farelo de arroz) e 3,0\% da fonte de nitrogênio (milhocina). Aspergillus niger var. phoenicis URM 4924 apresentou potencial biotecnológico para produção de fitases que poderão ser adicionadas a alimentação de animais não-ruminantes, desta maneira, contribuindo aumento do aproveitamento de nutrientes e dos índices de produção.

\section{Referências bibliográficas}

Adinarayana, K. \& Ellaiah, P. (2003). Production of alkaline protease by immobilized cells of alkalophilic Bacillus sp. Journal of Scientific \& Industrial Research, 62589-592.

Anto, H., Trivedi, U. B. \& Patel, K. C. (2006). Glucoamylase production by solid-state fermentation using rice flake manufacturing waste products as substrate. Bioresource Technology, 97(10):11611166.

Barros Neto et al., 2003

Bertolin, T. E., Schmidell, W., Maiorano, A. E., Casara, J. \& Costa, J. A. V. (2003). Influence of carbon, nitrogen and phosphorous sources on glucoamylase production by Aspergillus awamori in solid state fermentation. Zeitschrift für Naturforschung C, 58(9-10):708-712.

Castro, I. A., Silva, R. S. F., Tirapegui, J., Borsato, D. \& Bona, E. (2003). Simultaneous optimization of response variables in protein mixture formulation: constrained simplex method approach. International Journal of Food Science \& Technology, 38(2):103-110.

Choi, Y. M., Suh, H. J. \& Kim, J. M. (2001). Purification and properties of extracellular phytase from Bacillus sp. KHU-10. Journal of Protein Chemistry, 20(4):287-292. 
Dahiya, S., Singh, N. \& Rana, J. S. (2009). Optimization of growth parameters of phytase producing fungus using RSM. Journal of Scientific and Industrial Research, 68955-959.

El-Gindy, A. A., Ibrahim, Z. M., Ali, U. F. \& El-Mahdy, O. M. (2009). Extracellular phytase production by solid-state cultures of Malbranchea sulfurea and Aspergillus Niveus on cost-effective medium. Research Journal of Agriculture and Biological Sciences, 5(1):42-62.

Fan, C.-M., Wang, Y.-H., Zheng, C.-Y. \& Fu, Y.-F. (2013). Fingerprint motifs of phytases. African Journal of Biotechnology, 12(10):1138-1147.

Filipović, S. S., Ristić, M. D. \& Sakac, M. B. (2001). Technology of corn steep application in animal mashes and their quality. Roumanian Biotechnology Letters, 7705-710.

Fleuri, L. F. \& Sato, H. H. (2008). Estudo da influência de diferentes parâmetos na produção de enzimas líticas. Revista de Ciência e Tecnologia de Alimentos, 28299-310.

Heinonen, J. K. \& Lahti, R. J. (1981). A new and convenient colorimetric determination of inorganic orthophosphate and its application to the assay of inorganic pyrophosphatase. Analytical Biochemistry, 113(2):313-317.

Kim, D.-S., Godber, J. S. \& Kim, H.-R. (1999). Culture conditions for a new phytase-producing fungus. Biotechnology Letters, 21(12):1077-1081.

Lan, G. Q., Andullah, S., Jajaludin, S. \& Ho, Y. W. (2002). Optimization of carbon and nitrogen sources of phytase production by Mitsuokella jajaludini, a new rúmen bacterial species. Letters in Applies Microbiology, 35157-161.

Lei, X. G. \& Porres, J. M. (2003). Phytase enzymology, applications, and biotechnology. Biotechnology Letters, 25(21):1787-1794.

Luo, H., Huang, H., Yang, P., Wang, Y., Yuan, T., Wu, N., Fan, Y. (2007). A novel phytase appA from Citrobacter amalonaticus CGMCC 1696: gene cloning and overexpression in Pichia pastoris. Current Microbiology, 55(3):185-192.

Marlida, Y., Delfita, R., Adnadi, P. \& Ciptaan, G. (2010). Isolation, characterization and production of phytase from endophytic fungus its application for feed. Pakistan Journal of Nutrition, 9(5):471474.

Nampoothiri, K. M., Tomes, G. J., Roopesh, K., Szakacs, G., Nagy, V., Soccol, C. R. \& Pankey, A. (2004). Thermostable phytase production by Thermoascus aurantiacus in submerged fermentation. Applied Biochemistry and Biotechnology, 118(1-3):205-214.

NRC. (1994). Nutrients Requirements of Poultry (7th rev. ed.). Washington: Natl. Acad. Press, Washington, DC.

Papagianni, M., Nokes, S. E. \& Filer, K. (1999). Production of phytase by Aspergillus niger in submerged and solid-state fermentation. Process Biochemistry, 35(3-4):397-402.

Pereira Junior, 2008

Rostagno, H. S., Albino, L. F. T., Donzele, J. L., Gomes, P. C., Oliveira, R., Lopes, D. C., Euclides, R. F. (2017). Composição de alimentos e exigências nutricionais (3 ed. Vol. 1). Viçosa: Universidade Federal de Viçosa.

SAS. (2004). SAS/STAT User guide, Version 9.1.2. Cary, NC, USA: SAS Institute Inc.

Shah, P., Bhavsar, K., Soni, S. K. \& Khire, J. M. (2009). Strain improvement and up scaling of phytase production by Aspergillus niger NCIM 563 under submerged fermentation conditions. Journal of Industrial Microbiology \& Biotechnology, 36(3):373-380.

Singh, B. \& Satyanarayana, T. (2009). Characterization of a HAP-phytase from a thermophilic mould Sporotrichum thermophile. Bioresource Technology, 100(6):2046-2051.

Soni, S. K. \& Khire, J. M. (2007). Production and partial characterization of two types of phytase from Aspergillus niger NCIM 563 under submerged fermentation conditions. World Journal of Microbiology and Biotechnology, 23(11):1585-1593.

Thyagarajan, R. \& Namasivayam, S. K. R. N. (2010). Influence of carbon source phytase production by Aspergillus niger. International Journal of Biological Technology, 178-80. 
Tirado-González, D. N., Jáuregui-Rincón, J., Tirado-Estrada, G. G., Martínez-Hernández, P. A., Guevara-Lara, F. \& Miranda-Romero, L. A. (2016). Production of cellulases and xylanases by whiterot fungi cultured in corn stover media for ruminant feed applications. Animal Feed Science and Technology, 221, Part A147-156.

Vats, P. \& Banerjee, U. C. (2004). Production studies and catalytic properties of phytases (myoinositolhexakisphosphate phosphohydrolases): an overview. Enzyme and Microbial Technology, 35(1):3-14.

Zhang, G. Q., Dong, X. F., Wang, Z. H., Zhang, Q., Wang, H. X. \& Tong, J. M. (2010). Purification, characterization, and cloning of a novel phytase with low $\mathrm{pH}$ optimum and strong proteolysis resistance from Aspergillus ficuum NTG-23. Bioresource Technology, 101(11):4125-4131.

Recebido: 28 de janeiro, 2019.

Aprovado: 20 de fevereiro, 2019.

Publicado: 21 de março, 2019.

Licenciamento: Este artigo é publicado na modalidade Acesso Aberto sob a licença Creative Commons Atribuição 4.0 (CC-BY 4.0), a qual permite uso irrestrito, distribuição, reprodução em qualquer meio, desde que o autor e a fonte sejam devidamente creditados. 